\title{
Correlation based clustering of the Mongolian stock exchange for portfolio management
}

\author{
Enkhtuul Bukhsuren ${ }^{1}$, Batnyam Battulga ${ }^{2}$ and Oyun-Erdene Namsrai ${ }^{3}$ \\ ${ }^{1,2,3}$ Department of Information and Computer Science, School of Engineering and Applied Sciences, National \\ University of Mongolia
}

\begin{abstract}
Background/Objectives: This research paper analyzed the stock prices of Mongolia Stock Exchange TOP 20 index from 1 January 2012 to 31 December 2016, and estimated the return rate of these stocks. Methods/Statistical analysis: A hierarchical clustering was created from the correlation matrix of stock returns. From this clustering five stocks were selected for the portfolio construction and the rate of return was maximized using the Modern Portfolio Theory developed by Harry Markowitz. Findings: The weight of each stock in the portfolio was calculated for maximization the return rate of the portfolio, and 12 portfolios were constructed from these five stocks. Improvements/Applications: An investor can select appropriate one of these portfolios in accordance with his or her risk and return characteristics
\end{abstract}

\section{Index Terms}

Portfolio theory, hierarchical clustering, correlation matrix of stock returns, portfolio optimization, stock exchange

\footnotetext{
Corresponding author : Oyun-Erdene Namsrai

oyunerdene@seas.num.edu.mn

-Manuscript received April 26, 2018.

-Revised May 3, 2018; Accepted June 2, 2018.

-Date of publication June 30, 2018

(C) The Academic Society of Convergence Science Inc.

2546-1583 @ 2017 IJEMR. Personal use is permitted, but republication/redistribution requires IJEMR permission.
} 


\section{INTRODUCTION}

Given that the financial system of Mongolia is dominated by the banking sector and the deposit interest rate of Mongolia is higher than average deposit interest rate of developing and developed countries, the opportunity of raising funds from capital market is limited for new projects that may bring social and economic benefits in the long term, resulting in less development of capital market. The banking sector accounts for approximately 95 percent of the entire financial market of Mongolia and the remaining 5 percent is contributed by capital market, micro finance and insurance sector. Of which, less than 1 percent is contributed by the capital market.

In addition, the development of capital market is almost in stagnation (in terms of market capitalization, liquidity and infrastructure). For this reason, the number of research papers on the development of capital market has been increasing during the past years.

Trading securities and reliability of professional participants in the capital market, rate of return and risk of investment have been studied relatively well. However, still the portfolio construction decision remains one of important issue.

\section{LITERATURE REVIEW}

\section{A. Portfolio management}

One of the decision problems in financial market is how to choose portfolio management and asset selection. In other words, the portfolio selection theory is the answer to how the investor chooses the most optimal and efficient portfolio.

Harry Markowitz, an American economist, published research work about portfolio selection [1, $2]$. These publications proved that an investor can manage its expected return and dispersion (risk) in the case of certain condition.

A mathematic model developed by him is only the model that does not require "no arbitrage" condition in the financial math and showed how to use the diversification effectively. His pioneering work is known as a foundation of modern portfolio theory. As his model calculates the covariance of all assets in the portfolio, it is complicated to estimate such variance for a portfolio with many assets.

The Capital Asset Pricing Model (CAPM) was introduced by W. Sharpe [3] and J. Lintner [4], American economists, based on the works of Markowitz. This model suggests optimal portfolio construction with risky assets and is originated from Markowitz's theory.

\section{B. Literature review on the use of data mining methods in the stock market}

The stock exchanges were established thousands of years ago and evolved and developed with the effects of global economic crisis and other factors.

Traditional securities trading is originated from early 1980s and it now became an online trading due to the development of information and technology. Use of computer system in trading allowed to create and store a significant amount of data. Since 1990s the term "big data" was introduced and many scientific and research works focused on the question: "how to process such huge amount of data efficiently and to create a knowledge that meets the needs of people and helps decision-making".

In the past two decades, researchers began to apply data mining in stock markets. Data mining is the process of analyzing and discovering patterns in large data.

Traditionally, research methods used in the capital market were based on statistical methods, including, but not limited to, Random Walks theory [5], "Efficient Market Hypothesis" [6].

Prediction approaches are widely applied in stock research, particularly stock price prediction. Hsu implemented a hybrid of Self Organizing Map and genetic programming to predict stock prices in Taiwan Stock Exchange [7].

There are also research that used the Artificial Neural Network for stock market prediction[8-10].

S. R. Nanda, B. Mahanty, M.K. Tiwari used Kmeans, Self-Organizing Map (SOM) and Fuzzy CMeans to cluster stocks listed on Bombay Stock Exchange (BSE). The study aimed to build stock portfolios based on the clusters resulted from the clustering algorithms. The researchers then compared the investment return of each stock portfolio with the Sensex Index. The results showed that K-means performed better than Self Organizing Map (SOM) and Fuzzy C-Means [11].

Using genetic algorithm (GA), Oh, Kim and Min study proposes a portfolio optimization scheme for index fund management in 2005 [12]. Topaloglou, Vladimirou, and Zenios worked on a dynamic stochastic programming model for international portfolio management, a solution that determines capital allocations to international markets, the selection of assets within each market, and appropriate currency hedging levels [13].

\section{RESEARCH METHODOLOGY}

\section{A. Model developed by H. Markowitz}

H. Markowitz published his famous books "Portfolio Selection" in 1952 and "Portfolio Selection: Efficient Diversification of Investments" 
in 1959, laying the foundation of modern portfolio theory. He developed the portfolio selection theory in uncertain condition, identified the difference between risks of particular asset and portfolio in math equation and proved that the risk of a portfolio depends on the covariance of assets in that portfolio. To estimate the variation of return of the portfolio, the variation of individual assets and the covariance of return of such assets are considered. For risk and return characteristics of a portfolio, the model developed by Markowitz suggests the maximization of expected return and minimization of risk of the portfolio.

Key formula for maximization of expected rate of return of portfolio is:

$$
E\left(R_{p}\right)=\sum_{i=1}^{n} \omega_{i} E\left(R_{i}\right)
$$

Where $\omega_{i}$ must satisfy the following constraint.

$$
\left\{\begin{array}{c}
\operatorname{var}\left(R_{p}\right)=\sum_{i=1}^{n} \omega_{i}^{2} \operatorname{var}\left(R_{i}\right)+ \\
+\sum_{i=1}^{n} \sum_{\substack{j=1 \\
i \neq j}}^{n} \omega_{i} \omega_{j} \operatorname{cov}\left(R_{i}, R_{j}\right) \leq \sigma_{p}^{2} \\
\omega_{1}+\omega_{2}+\cdots+\omega_{n}=1 \\
\omega_{i} \geq 0
\end{array}\right.
$$

Where $\omega_{i}-i$ is the weight of asset in the portfolio, $E\left(R_{i}\right)-i$ is expected return of asset in the portfolio, $\operatorname{cov}\left(R_{i}, R_{j}\right)$ is the covariance between asset $i$ and $j$

\section{B. Hierarchical clustering analysis}

In data mining and statistics, hierarchical clustering is one of the cluster analysis methods which seeks to build a hierarch of clusters.

\section{Linkage criteria}

The linkage criterion determines the distance between sets of observations as a function of the pairwise distances between observations. Some commonly used linkage criteria between two sets of observations $\mathrm{A}$ and $\mathrm{B}$ are:

Table 1. LINKAGE CRITERIA

\begin{tabular}{cc}
\hline \hline Names & Formula \\
\hline $\begin{array}{c}\text { Maximum or } \\
\text { complete-linkage } \\
\text { clustering }\end{array}$ & $\max \{d(a, b): a \in A, b \in B\}$ \\
\hline $\begin{array}{c}\text { Minimum or single- } \\
\text { linkage clustering }\end{array}$ & $\min \{d(a, b): a \in A, b \in B\}$ \\
\hline $\begin{array}{c}\text { Mean or average } \\
\text { linkage clustering }\end{array}$ & $\frac{1}{|A||B|} \sum_{a \in A} \sum_{b \in B} d(a, b)$ \\
\hline $\begin{array}{c}\text { Centroid linkage } \\
\text { clustering }\end{array}$ & $\left\|c_{s}-c_{t}\right\|$, с болон т бүлэглэлтийн \\
төвийн утга нь $c_{s}, c_{t}$
\end{tabular}

where $d$ is the chosen metric.

The common method is agglomerative or "bottom up" approach which visualize the clustering and subclustering, linkage between clusters and hierarchy of merges and splits in a tree diagram. This diagram is called a dendrogram.

As suggested by Mantegna, the following equation is used to convert the correlation coefficient into distance function [14].

$$
d_{(i, j)}=\sqrt{2 *\left(1-\rho_{(i, j)}\right)}
$$

Given that we will create a cluster based on the correlation of stock returns, it is better to establish the criteria for space between data sets of observation $\mathrm{A}$ and $\mathrm{B}$ by using the hierarchical clustering method with one linkage or by the minimum value. After constructing a correlation matrix of stock returns, it shall be converted into a distance matrix using the equation (3) and a cluster shall be created by hierarchical clustering method with one linkage.

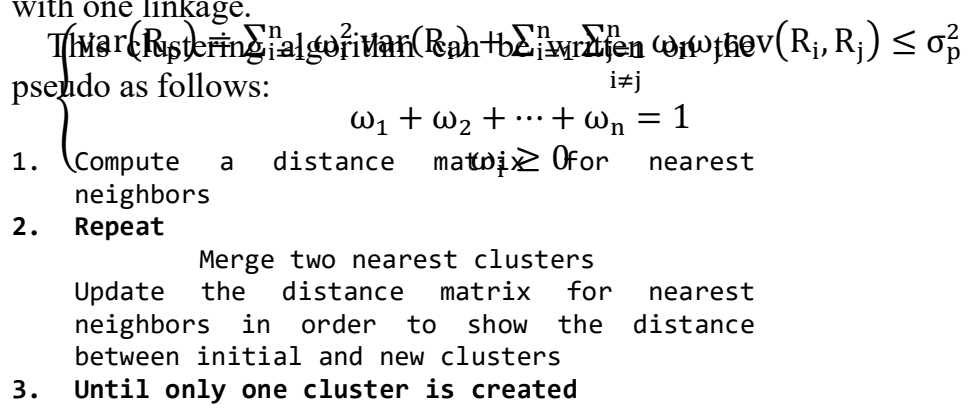

\section{DATA DESCRIPTION}

In this paper stock data for companies listed in Mongolian stock exchange (MSE) was collected from web site. In this research work, we analyzed actual stock prices of MSE TOP 20 index from 1 January 2012 to 31 December 2016.

\section{EXPERIMENTAL RESULTS}

\section{A. Creating a hierarchical clustering}

The stock returns were calculated from the selected stock prices, and also a correlation matrix of stock returns was constructed.

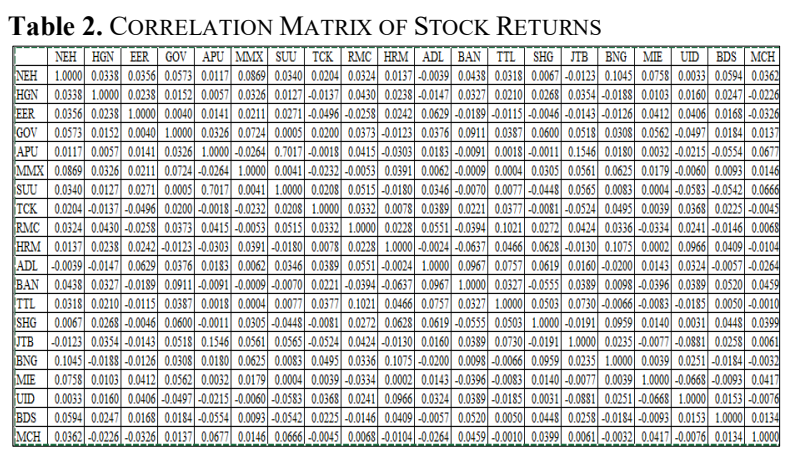


The distance matrix was constructed from the correlation matrix of stock returns using the equation (3), and the results of such matrix were shown in Table 3.

Table 3. DISTANCE MATRIX

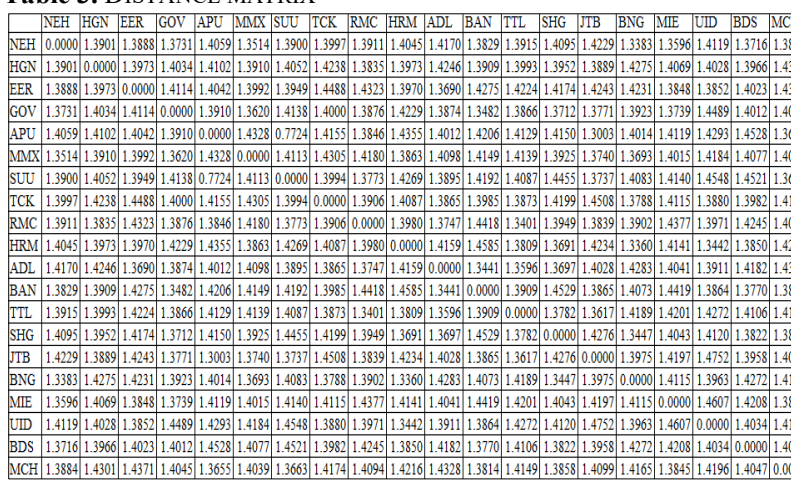

Given that we are trying to construct a diversified portfolio, it is better to establish the criteria for distance between data sets of observation $\mathrm{A}$ and $\mathrm{B}$ by using the hierarchical clustering method with one linkage or by the minimum value.

From the distance matrix, the stocks with lowest value were selected and clustered. In this process, the correlation coefficient between SUU and APU stocks has the lowest distance value $(0.7724)$, so that these two stocks are included in one cluster.

The distance between newly created pairs and initial points shall be recomputed. For example, $\mathrm{d}(\mathrm{NEH},(\mathrm{SUU}, \mathrm{APU}))=\min (\mathrm{d}(\mathrm{NEH}, \mathrm{SUU}), \mathrm{d}(\mathrm{NEH}$, $\mathrm{APU}))=\min (1.3900,1.4059)=1.3900$, meaning that new distance between NEH and (SUU, APU) is 1.3900 .

Using the above method, the distance between other new pairs and previous points shall be computed. This algorithm shall be repeated until the final step when there are no points to cluster

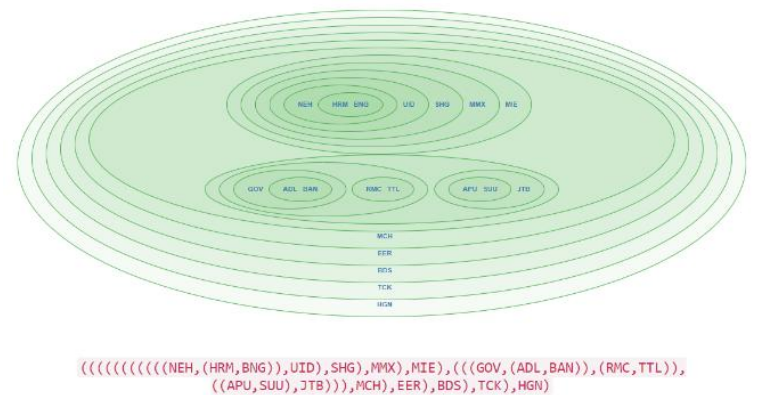

Fig. 1. Results of hierarchical clustering

Clustering -1: ((APU, SUU), JTB)

Clustering -2: ((ADL, BAN), GOV)

Clustering - 3: (RMC, TTL)

Clustering - 4: (HRM, BNG)

Clustering - 5: (((HRM, BNG), NEH), UID)...

\section{B. Portfolio optimization}

A portfolio shall be constructed by selecting stocks from the clusters created by hierarchical clustering algorithm. The average expected return and risk of a portfolio (which was constructed in equal weights of selected stocks) were estimated by Markowitz's model. After that, the maximum expected return of such portfolio was computed by portfolio optimization while keeping the risk of equally weighted portfolio constant.

From hierarchical clusters, 5 stocks (Baganuur JSC, APU JSC, Maximpex JSC, Tavan Tolgoi JSC and Darkhan Nekhii JSC) were selected for portfolio construction. When keeping equal weights of these stocks in the portfolio (meaning that each stock has $20 \%$ weight in the portfolio), the expected return of the portfolio was $\mathbf{- 0 . 0 0 0 7 4 0 5 1 1 9}$ and the expected risk of the portfolio was $\mathbf{0 . 0 0 0 5 4 2 7 0 8 3}$.

We estimated the maximum return of portfolio by changing the weights of 5 stocks in the portfolio while keeping the risk of the portfolio constant. The results are shown below:

Expected return of the portfolio: $\mathbf{0 . 0 0 0 0 1 0 1 4 5 9}$

Expected risk of the portfolio: $\mathbf{0 . 0 0 0 5 4 2 7 0 8 3}$

\section{Weights of stocks in optimal portfolio}

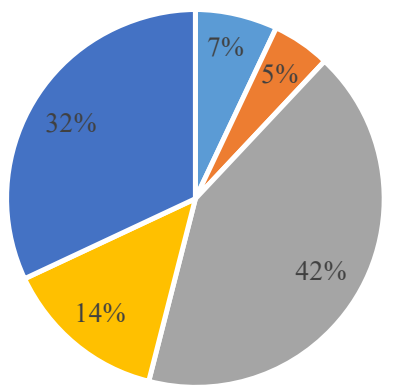

$$
\begin{aligned}
& \text { " Baganuur JSC }=\text { APU JSC } \\
& \text { " Maximpex JSC }=\text { Tavantolgoi JSC } \\
& \text { - Darkhan Nekhii JSC }
\end{aligned}
$$

Fig. 2. Weights of stocks in optimal portfolio

Within the given risk level, an optimal portfolio (with maximum rate of return) can be constructed in the following weights of stocks: $7 \%$ from Baganuur JSC, 5\% from APU JSC, 42\% from Makhimpex JSC, $14 \%$ from Tavantolgoi JSC and 32\% from Darkhan Nekhii JSC respectively. 12 portfolios were constructed from these 5 stocks, so that an investor can select appropriate one of these portfolios in accordance with his or her risk and return characteristics. 
Table 4. EXPECTED RETURN, RISK AND WEIGHTS OF THE PORTFOLIO

\begin{tabular}{|c|c|c|c|c|c|c|c|}
\hline Portfolio & $\begin{array}{l}\text { Expected return } \\
\text { of the portfolio }\end{array}$ & $\begin{array}{l}\text { Expected risk of } \\
\text { the portfolio }\end{array}$ & APU JSC & $\begin{array}{c}\begin{array}{c}\text { Bagantuur } \\
\text { JSC }\end{array} \\
\end{array}$ & $\begin{array}{c}\text { Tavantol } \\
\text { goi JSC }\end{array}$ & \begin{tabular}{c|} 
Darkhan \\
Nekhii \\
JSC
\end{tabular} & $\begin{array}{c}\text { Maximpex } \\
\text { JSC }\end{array}$ \\
\hline Oattolio 1 & -0.0007405119 & 005059638 & $16.435 \%$ & $17.921 \%$ & $23.684 \%$ & $11.384 \%$ & $30.576^{4}$ \\
\hline Portfolio 2 & -0.0006722703 & 0.0004918109 & $15.419 \%$ & $16.935 \%$ & $22.774 \%$ & $13.242 \%$ & 31.629 \\
\hline Portfolio 3 & -0.000604028 & 11566 & $14.403 \%$ & $15.949 \%$ & $21.864 \%$ & $15.101 \%$ & $32.683^{4}$ \\
\hline Portfolio 4 & -0.0005357870 & 0.0004740010 & $13.387 \%$ & $14.963 \%$ & $20.955 \%$ & $16.959 \%$ & $33.736^{6}$ \\
\hline Portfolio 5 & -0.0004675454 & 0.0004703441 & $12.371 \%$ & $13.978 \%$ & $20.045 \%$ & $18.817 \%$ & 34.789 \\
\hline Portfolio 6 & -0.0003993038 & 0.0004701859 & $11.355 \%$ & $12.992 \%$ & $.135 \%$ & $20.675 \%$ & $35.843^{4}$ \\
\hline Ontfolio 7 & -0.0003310622 & 0.0004735263 & $10.339 \%$ & $12.006 \%$ & $18.226 \%$ & $22.533 \%$ & $36.896^{6}$ \\
\hline ortelio 8 & -0.0002628206 & 0.000 & $9.323 \%$ & $11.02 \%$ & $17.316 \%$ & $24.391 \%$ & $37.949 \cdot$ \\
\hline Portfolio 9 & -0.0001945790 & 0.00049 & $8.307 \%$ & $10.034 \%$ & $16.406 \%$ & $26.249 \%$ & $39.003^{4}$ \\
\hline Portfolio 10 & -0.0001263373 & & $7.291 \%$ & $9.049 \%$ & $15.497 \%$ & $28.108 \%$ & $40.056^{4}$ \\
\hline tfolio 11 & -0.0000580957 & 0.0005218746 & $6.275 \%$ & $8.063 \%$ & $14.587 \%$ & $29.966 \%$ & $41.11^{\prime}$ \\
\hline Ortfolio 12 & 0.0000101459 & 0.0005427083 & $5.259 \%$ & $7.077 \%$ & $13.677 \%$ & $31.824 \%$ & $42.163^{4}$ \\
\hline
\end{tabular}

\section{CONCLUSION}

This research work analyzed the stock price data of MSE TOP 20 index for the sample period of 2012 to 2016 , and created a hierarchical clustering. Then the stocks were selected from each cluster and the weight of each stock in the optimal portfolio was computed using Markowitz's model. It can be concluded that an optimal portfolio can be constructed effectively by using hierarchical clustering. In addition, 12 portfolios were constructed from these 5 stocks, so that an investor can select appropriate one of these portfolios in accordance with his or her risk and return characteristics.

\section{REFERENCES}

[1] Markowitz, H. (1952). Portfolio Selection. Journal of Finance, 77-91.

[2] Markowitz, H. (1959). Portfolio allocation: Efficient diversification of investments. A Cowles Foundation Monograph. New York: John Wiley \& Sons.

[3] Sharpe, W. F. (1964). Capital asset prices: A theory of market equilibrium under conditions of risk. The Journal of Finance, 19(3), 425-442.

[4] Lintner, J. (1965). The valuation of risk assets and the selection of risky investments in stock portfolios and capital budgets. The Review of Economics and Statistics, 13-37.

[5] Fama, E. (1965). The behavior of stock prices. Journal of Business, 34-105.

[6] Basu, S. (1977). Investment performance of common stocks in relation to their price-earnings ratios: a test of the efficient market hypothesis. Journal Finance, 663-682.

[7] Hsu, C. (2011). A hybrid procedure for stock price prediction by integrating self-organizing map and genetic programming. Exp Syst Appl 38(11), 14026-14036.

[8] Kohara, K. I. (1997). Stock price prediction using prior knowledge and neural networks. Int. J. Intell. Syst. Account. Finance Manag., vol. 6, 11-12.

[9] Yoon, G. S. (1991). Predicting stock price performance: A neural network approach. In: System Sciences, Proceedings of the twenty-fourth annual Hawaii international conference (pp. 156-162). IEEE.

[10] Zhang, Y., \& Wu, L. (2009). Stock market prediction of S\&P 500 via combination of improved bco approach and bp neural network. Exp Syst Appl , 36(5), 8849-8854.

[11] Nanda, S. M. (2010). Clustering indian stock market data for portfolio management. Exp Syst Appl 37(12), 8793-8798.

[12] Oh, K., Kim, T., \& Min, S. (2005). Using genetic algorithm to support portfolio optimization for index fund Management. Expert Systems with Applications, 28, 371-379.
[13] Topaloglou, N., Vladimirou, H., \& Zenios, S. (2008). A dynamic stochastic programming model for international portfolio management. European Journal of Operational Research, 1501-1524.

[14] Mantegna, R. (1999). Hierarchical structure in financial markets. Eur. Phys. J. B 11, 193-197. 